ISSN: $1410-8917$

Jurnal Kimia

Sains \& Aplikasi
Jurnal Kimia Sains dan Aplikasi Journal of Scientific and Applied Chemistry

Journal homepage: http://ejournal.undip.ac.id/index.php/ksa

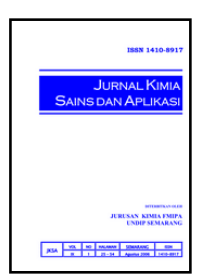

\title{
Adsorpsi Alkil Benzena Sulfonat Menggunakan Zeolit Termodifikasi Cetyltrimethylammonium
}

\author{
Anis Komariah ${ }^{a}$, Sriatun ${ }^{\mathrm{a},{ }^{*}}$, Pardoyo $^{\mathrm{a}}$ \\ a Inorganic Chemistry Laboratory, Chemistry Department, Faculty of Sciences and Mathematics, Diponegoro University, Jalan Prof. \\ Soedarto, Tembalang, Semarang 50275 \\ * Corresponding author: sriatun@live.undip.ac.id
}

$\overline{\text { Article Info }}$

ZMS (Zeolite

Modified

Surfactant),

Adsorption, Alkyl

Benzene Sulfonate

\section{Abstract}

In this research, modification of $\mathrm{NH}_{4} \mathrm{Cl}$ (H-Zeolite) activated zeolite with $\mathrm{CTAB}$ (Cetyltrimethylammonium Bromide) surfactant of various concentrations of $0.25 \mathrm{mM}$ (ZMS-1), $1 \mathrm{mM}$ (ZMS-2) and $100 \mathrm{mM}$ (ZMS-3) as an Alkyl Benzene Sulfonate (ABS) compound adsorbent has been conducted.. Characterization was performed on $\mathrm{H}$-Zeolite and ZMS using FTIR spectrophotometer. The main parameters in this study were variation of concentration of $\mathrm{ABS}(50,75$, and $100 \mathrm{ppm})$ and contact time $(15,30,45,60$, 75 , and $90 \mathrm{~min})$. The adsorbed ABS concentration was analysed by UV-Vis spectrophotometer using the MBAS (Methylene Blue Active Substance) method. The result of FTIR spectra of modified surfactant modified zeolite (ZMS) showed peak at wave number $2931,80 \mathrm{~cm}^{-1} ; 2854,65 \mathrm{~cm}^{-1}$ and $1404,18 \mathrm{~cm}^{-1}$ indicating the presence of $\mathrm{CTAB}$ group on zeolite. The maximum concentration and optimum time ABS that could be absorbed by 0.1 gram ZMS was $50 \mathrm{ppm}$ in $25 \mathrm{~mL}$ at 60 minutes with adsorption percentage of $84.04 \%$ for H-Zeolite; $96.42 \%$ for ZMS-1; $96.48 \%$ for ZMS-2; And $97.29 \%$ for ZMS-3. ZMS performance tended to increase with CTAB concentration in zeolites.

\section{Abstrak}

Dalam penelitian ini dilakukan modifikasi zeolit alam teraktivasi $\mathrm{NH} 4 \mathrm{Cl}$ ( $\mathrm{H}$-Zeolit) dengan surfaktan CTAB (Cetyltrimethylammonium Bromide) berbagai konsentrasi yaitu sebesar 0,25 mM (ZMS-1), 1 mM (ZMS-2), dan $100 \mathrm{mM}$ (ZMS-3) sebagai adsorben senyawa ABS (Alkil Benzena Sulfonat). Karakterisasi dilakukan terhadap H-Zeolit dan ZMS menggunakan spektrofotometer FTIR. Parameter utama dalam penelitian ini adalah variasi konsentrasi ABS (50, 75, dan 100 ppm) dan waktu kontak (15, 30, 45, 60, 75 , dan 90 menit). Konsentrasi ABS yang teradsorpsi dianalisis dengan spektrofotometer UV-Vis menggunakan metode MBAS (Methylene Blue Active Substance). Hasil spektra FTIR zeolit alam termodifikasi surfaktan (ZMS) menunjukkan puncak pada bilangan gelombang 2931,80 cm-1; 2854,65 $\mathrm{cm}^{-1}$ dan $1404,18 \mathrm{~cm}^{-1}$ yang mengindikasikan keberadaan gugus CTAB pada zeolit. Konsentrasi maksimum dan waktu optimum ABS yang dapat dijerap oleh per 0,1 gram ZMS adalah $50 \mathrm{ppm}$ dalam $25 \mathrm{~mL}$ pada waktu 60 menit dengan persen adsorpsi sebesar 84,04\% untuk H-Zeolit ; 96,42\% untuk ZMS-1; 96,48\% untuk ZMS-2; dan 97,29\% untuk ZMS-3. Performa ZMS cenderung meningkat dengan konsentrasi CTAB pada zeolit.

\section{Pendahuluan}

Detergen yang digunakan rumah tangga (masyarakat umum dan usaha laundry pakaian), umumnya mengandung surfaktan yang merupakan zat aktif permukaan seperti Alkil Benzena Sulfonat (ABS) yang berbahaya bagi organisme air karena dapat menurunkan konsentrasi oksigen dalam air dan 
memberikan efek karsinogenik, sehingga kehidupan organisme air akan terganggu bahkan mati [1]. Senyawa ABS mempunyai struktur rantai bercabang dan stabil, sehingga memiliki tingkat biodegradable yang sangat rendah. Di Indonesia $\mathrm{ABS}$ masih digunakan karena relatif murah dan stabil saat proses produksinya. Metode konvensional untuk degradasi surfaktan dari air antara lain oksidasi elektrokimia, teknologi membran, presipitasi kimia, photokatalitik, adsorpsi dan metode biologis.

Menurut Taffarel dan Rubio [2], adsorpsi senyawa organik seperti surfaktan anionik paling efektif menggunakan resin penukar ion zeolit ataupun karbon aktif. Selain itu telah dilakukan adsorpsi surfaktan linier alkil benzene sulfonat (LAS) menggunakan karbon nanotube (CNT) termodifikasi karboksil [3], menggunakan karbon dari tempurung kelapa [4], menggunakan bentonit alam [4] dan menggunakan magnetit [5].

Zeolit merupakan kristal aluminasilikat yang mempunyai struktur tiga dimensi, tersusun atas unsur utama alumunium, silicon dan oksigen serta pengotor seperti air dan kation penyeimbang golongan alkali atau alkali tanah. Xia dkk. [6], Zhang dkk. [7], dan Zhou [8] menyatakan bahwa faktor luas permukaan, keasaman, sifat porous dan KPK (Kapasitas Penukar Kation) zeolit yang tinggi menyebabkan bahan ini banyak diaplikasikan sebagai penyerap selektif, penukar ion, serta katalis. Zeolit alam biasanya mempunyai karakter rasio Si/Al yang rendah, misalnya zeolit alam Bayat, Klaten, Jawa Tengah, mempunyai rasio Si/Al 2,852 [9]. Kandungan alumina pada kerangka zeolit alam yang tinggi mengakibatkan konsentrasi kation penyeimbang pada permukaan zeolit juga tinggi, sehingga menyebabkan strukturnya berkarakter hidrofilik dan mempunyai kecenderungan bermuatan negatif. Dengan demikian perlu dilakukan modifikasi terhadap permukaan zeolit agar bersifat lebih hidrofob dan bermuatan positif sehingga selektif dalam mengadsorpsi senyawa anionik organik non polar.

Modifikasi dengan surfaktan kationik CTAB (cetyltrimethylammonium Bromide) pada permukaan MCM-49 [10], pada MCM-41 via mikroemulsi [11], pada Na-monmorilonit [12] dan pada zeolit alam oleh [9, 13]. Sementara itu Taffarel dan Rubio [2] dalam modifikasi zeolit-CTAB (Cetyltrimethylammonium Bromide) sebagai penyerap surfaktan anionik SDBS (Sodium Deodecyl Benzene Sulfonate) sedangkan Setiawati dkk. [14] sebagai penyerap fosfat.

Dalam penelitian ini dilakukan modifikasi zeolit alam menggunakan surfaktan kationik cetiltrimethylammonium bromide (CTAB) dan menguji daya jerapnya sebagai adsorben senyawa organik surfaktan anionik Alkil Benzena Sulfonat (ABS) yang terkandung dalam detergen.

\section{Metodologi Penelitian}

Bahan: Zeolit alam Bayat (Klaten), akuades, akuademineral, CTAB (Cetyltrimethylammonium
Bromide), NH4Cl, Alkil Benzena Sulfonat (ABS), AgNO3, metilen biru, $\mathrm{NaH}_{2} \mathrm{PO} 4 . \mathrm{H} 2 \mathrm{O}, \mathrm{H}_{2} \mathrm{SO}_{4}$ p.a, $\mathrm{CHCl}_{3}$.

Alat: Peralatan gelas, batch shaker, sentrifugasi, ayakan ukuran 150 mesh, oven, furnace, spektrofotometer FTIR, spektrofotometer UV-Visible Shimadzhu.

\section{Prosedur Penelitian}

Preparasi Zeolit Alam. Zeolit alam Bayat dicuci dengan aquades dan dikeringkan suhu 1050C selama 10 jam, kemudian diayak menggunakan ayakan lolos 150 mesh.

Pengaktivasian. 30 gram zeolit direndam dalam $600 \mathrm{~mL}$ larutan $\mathrm{NH} 4 \mathrm{Cl}$ 1,5 M selama 12 jam dan diaduk $350 \mathrm{rpm}$ pada suhu kamar. Selanjutnya disaring dan dicuci dengan aquademineralisasi hingga filtrate menunjukkan $\mathrm{pH}$ netral (diperiksa dengan AgNO3). Residu dikalsinasi suhu $350^{\circ} \mathrm{C}$ selama 9 jam. Hasil pengaktivan selanjutnya kita sebut $\mathrm{H}-$ Zeolit.

Modifikasi Zeolit Alam Teraktivasi Dengan Surfaktan CTAB. Sebanyak 21 gram zeolit dibagi kedalam tiga buah erlenmeyer dan ditambahkan CTAB dengan konsentrasi yaitu 0,25 mM, $1 \mathrm{mM}, 100 \mathrm{mM}$ (selanjutnya disebut ZMS-1, ZMS-2, dan ZMS-3). Campuran diaduk dalam shaker $150 \mathrm{rpm}$ selama 24 jam, dicuci hingga filtrat tidak menunjukkan endapan putih $\mathrm{AgBr}$ (diperiksa dengan $\mathrm{AgNO}_{3}$ ) dan residunya dikeringkan suhu $70^{\circ} \mathrm{C}$ selama 5 jam.

Karakterisasi Zeolit. H-Zeolit, ZMS-1, ZMS-2, dan ZMS-3 dikarakterisasi menggunakan instrument FTIR.

Pembuatan Larutan Standar ABS. Persiapan uji dilakukan dengan membuat larutan standar ABS berbagai variasi konsentrasi yaitu 0,$4 ; 0,8 ; 1,2 ; 1,6$; dan 2,0 ppm melalui pengenceran larutan induk ABS 1000 ppm.

Analisis Konsentrasi ABS Melalui Metode MBAS (Methylene Blue Active Substance). $10 \mathrm{~mL}$ sampel ABS dimasukkan kedalam corong pisah lalu ditambahkan 2,5 mL larutan metilen biru (0,0125 g metilen biru : 12,5 g $\mathrm{NaH} 2 \mathrm{PO} 4 . \mathrm{H} 2 \mathrm{O}: 1,7 \mathrm{~mL} \mathrm{H} 2 \mathrm{SO}_{4}$ : aquades hingga $250 \mathrm{ml}$ dalam labu ukur), dan ditambahkan $5 \mathrm{~mL}$ kloroform, kemudian digojok dan dikeluarkan gasnya sebanyak $2 \mathrm{x}$ 1,5 menit dan didiamkan sampai terbentuk dua fasa air di atas dan fasa kloroform di bawah. Fasa kloroform ditampung dicorong pisah lainnya, sedangkan fasa air di buang. Fasa kloroform ditambah dengan $5 \mathrm{~mL}$ larutan pencuci $\left(12,5 \mathrm{~g} \mathrm{NaH} 2 \mathrm{PO}_{4} \cdot \mathrm{H} 2 \mathrm{O}: 1,7 \mathrm{~mL} \mathrm{H} 2 \mathrm{SO}_{4}\right.$ : aquades hingga $250 \mathrm{~mL}$ dalam labu ukur) dan digojog kembali sambil dibuang gasnya selama 1,5 menit dan didiamkan. Lapisan bawah ditampung dalam labu ukur $10 \mathrm{~mL}$ dan diencerkan sampai tanda tera dengan kloroform, sedangkan fasa atas dibuang. Larutan hasil pengenceran siap diuji dengan spektrofotometer UV-Vis.

Pengaruh Variasi Konsentrasi Larutan ABS. Sebanyak 0,1 g zeolit hasil modifikasi dicampurkan dengan $25 \mathrm{~mL}$ larutan ABS (Alkil Benzena Sulfonat) 50, 
75, dan 100 ppm. Campuran selanjutnya diaduk dalam stirrer dengan kecepatan $150 \mathrm{rpm}$ dengan waktu 60 menit. Kemudian disentrifugasi selama 10 menit dan larutannya diuji dengan menggunakan metode MBAS dan instrumen spektrofotometer UV-Vis.

Pengaruh Variasi Waktu Kontak. Sebanyak 0,1 g zeolit hasil modifikasi dicampurkan dengan konsentrasi optimum alkil benzena sulfonat. Campuran selanjutnya diaduk dalam stirrer dengan kecepatan 150 rpm dengan variasi waktu 15, 30, 45, 60, 75, dan 90 menit. Kemudian disentrifugasi selama 10 menit dan larutannya diuji dengan menggunakan metode MBAS dan instrumen spektrofotometer UV-Vis.

\section{Hasil dan Pembahasan}

Preparasi zeolit dilakukan untuk menghilangkan pengotor organik, memperbesar ukuran pori, dan memperluas permukaan. Proses ini dapat disebut pula aktivasi zeolit secara fisika. Hasilya adalah butiran zeolit bebas pengotor organik dengan luas permukaan dan ukuran pori yang seragam sekitar $106 \mu \mathrm{m}$ atau 150 mesh.

\section{Aktivasi Zeolit}

Aktivasi zeolit secara kimia dapat dilakukan dengan pengasaman yang menyebabkan terjadinya pertukaran kation penyeimbang dengan $\mathrm{H}^{+}$. Tujuan pengaktivasian ini juga agar $\mathrm{H}^{+}$dalam zeolit dapat bertukar dengan kation CTAB untuk keperluan proses modifikasi, karena $\mathrm{H}^{+}$merupakan gugus pergi yang baik. Pertukaran kation pada zeolit menggunakan $\mathrm{NH}_{4} \mathrm{Cl}$ pada temperatur ruang dapat menggantikan kation dengan $\mathrm{NH}_{4}^{+}$sehingga didapatkan $\mathrm{NH}_{4}{ }^{+}-$zeolit. Pengaktifan ini menurut tidak merusak struktur tetapi dapat lebih memurnikan zeolit dari pengotor-pengotornya. Pembentukan $\mathrm{H}$-zeolit selanjutnya dilakukan secara termal yaitu pada suhu $3500 \mathrm{C}$, hal ini dilakukan agar $\mathrm{NH} 3$ dapat terlepas dan menyisakan $\mathrm{H}+$ yang berinteraksi elektrostatik dengan permukaan zeolit.

\section{Modifikasi H-Zeolit Menggunakan Surfaktan CTAB}

Modifikasi $\mathrm{H}$-zeolit ini dilakukan melalui pertukaran kation menggunakan surfaktan kationik CTAB (Cetyltrimethylammonium Bromide) dengan harapan dapat mengubah sifat zeolit menjadi lebih hidrofob dan berkarakter parsial positif akibat permukaan zeolit yang terlapisi molekul surfaktan dalam bentuk bilayer sehingga dapat mengikat anion. Menurut Taffarel dan Rubio [2], pada konsentrasi surfaktan rendah, kation surfaktan dapat dipertukarkan dengan kation penyeimbang dari zeolit alam sehingga akan terbentuk monolayer kation surfaktan pada permukaan eksternal zeolit. Pada konsentrasi yang lebih tinggi yaitu pada saat CMC (Critical Micelles Concentration) atau diatas CMC molekul surfaktan yang melekat dengan interaksi elektrostatik ke permukaan eksternal akan membentuk bilayer atau lebih, di mana lapisan luar molekul surfaktan terikat oleh interaksi hidrofobik . Ilustrasi interaksi ini terdapat pada Gambar 1. Muatan permukaan eksternal zeolit berubah dari negatif menjadi positif dan sekarang mempunyai kapasitas tukar anion.

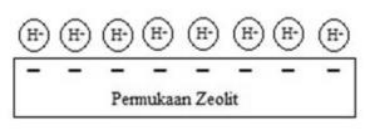

H-Zeolit

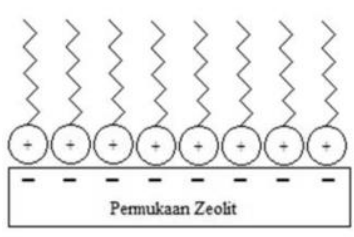

Penambahan CTAB tepat CMC (Pembentukan monolayer)

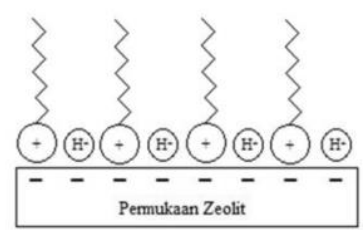

Penambahan CTAB dibawah CMC

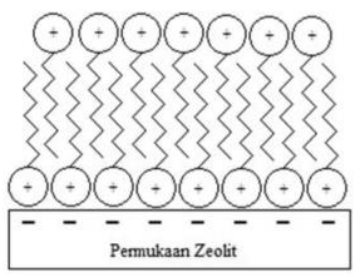

Penambahan CTAB diatas CMC

(Pembentukkan Bilayer)
Gambar 1. Skema Konfigurasi CTAB pada permukaan zeolit

Spektra infra merah zeolit dapat diamati pada rentang bilangan gelombang $300-1300 \mathrm{~cm}^{-1}$ yang mengintrepretasikan daerah utama serapan ikatan tetrahedral dari komponen utama penyusun zeolit yaitu $\mathrm{SiO}_{4}$ dan $\mathrm{AlO}_{4}$ [2]. Perbandingan hasil FTIR antara zeolit alam teraktivasi ( $\mathrm{H}-$ Zeolit) dengan zeolit termodifikasi CTAB di bawah CMC, tepat CMC dan diatas CMC ditunjukkan dalam Gambar 2.

Spektra FTIR untuk zeolit alam teraktivasi dan zeolit termodifikasi CTAB membuktikan bahwa telah terjadi pertukaran kation $\mathrm{H}^{+}$dengan kation $\mathrm{CTA}^{+}$ (Cetiltrimetilammonium) dari CTAB pada zeolit aktif, dengan membandingkan spektra surfaktan CTAB dari Taffarel dan Rubio [2] pada Gambar 3, yang menunjukkan ciri khas serapan kristal CTAB yakni pada panjang gelombang 2931,80 $\mathrm{cm}^{-1}$ dan $2854,65 \mathrm{~cm}^{-1}$ dimana pita serapan ini merupakan vibrasi asimetrik dan simetrik $-\mathrm{CH}_{2}$ serta vibrasi ulur asimetrik dan simetrik pada terminal gugus metil dari trimetilammonium $\left(\mathrm{CH}_{3}-\mathrm{R}\right)$. 


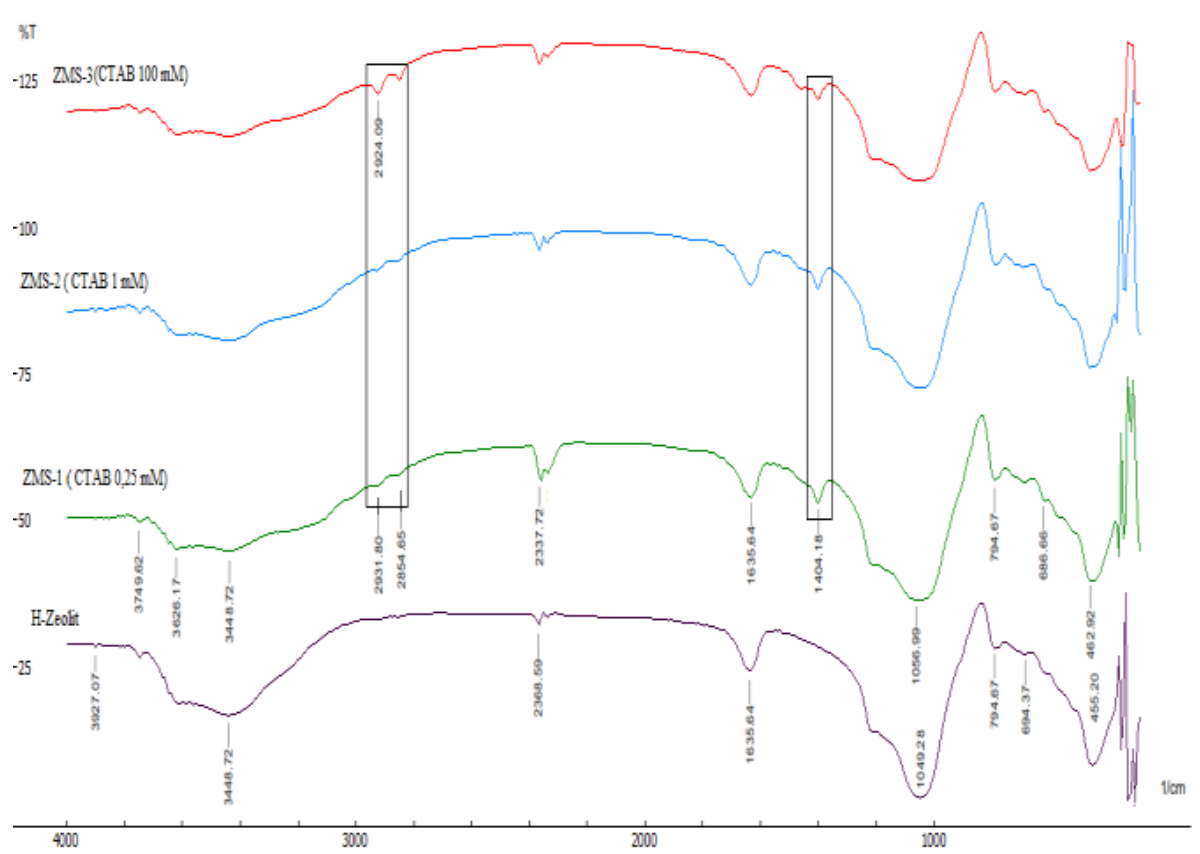

Gambar 2. Spektra FTIR (a) H-Zeolit, (b) ZMS-1, (c) ZMS-2, dan (d) ZMS-3

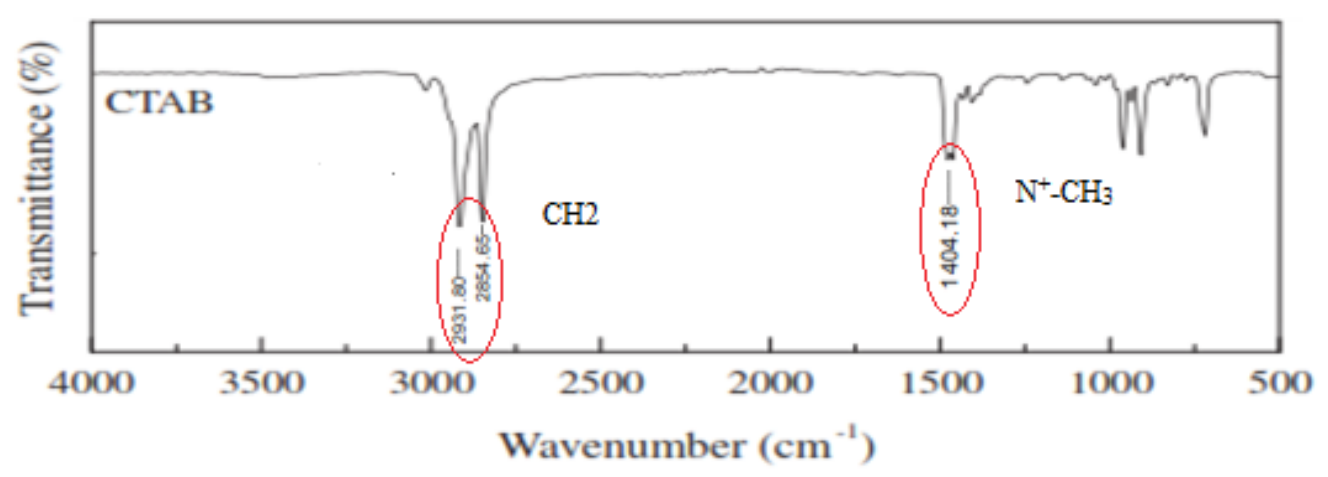

Gambar 3. Spektra FTIR kristal CTAB murni [2]

Pada spektra ZMS-3 terlihat puncak serapan pada bilangan gelombang $2931,80 \mathrm{~cm}^{-1}$ dan $2854,65 \mathrm{~cm}^{-1}$ semakin tajam, hal ini menegaskan jika surfaktan CTAB berhasil teradsorp ke permukaan zeolit karena menurut Hongping $d k k$. [15] pada konsentrasi CTAB yang tinggi, kisaran frekuensi berada pada bilangan gelombang yang lebih rendah karena pita absorbsi rentangan $\mathrm{CH}_{2}$ asimetrik berada pada all-trans conformation. Namun, pada konsentrasi CTAB rendah, frekuensi bergeser secara signifikan pada bilangan gelombang yang lebih tinggi, yang mengindikasikan bahwa sejumlah besar rantai amina berada pada konformer gauche. Pada panjang gelombang $1404,18 \mathrm{~cm}^{-1}$ dalam spektra FTIR ZMS-1, ZMS-2, maupun ZMS-3 [16] memperkuat asumsi bahwa zeolit telah berhasil dimodifikasi dengan CTAB karena merupakan vibrasi $\mathrm{N}-\left(\mathrm{CH}_{3}\right)$ tekuk yang terdapat pada gugus aktif rantai surfaktan CTAB.
Pengaruh Variasi Konsentrasi Larutan ABS

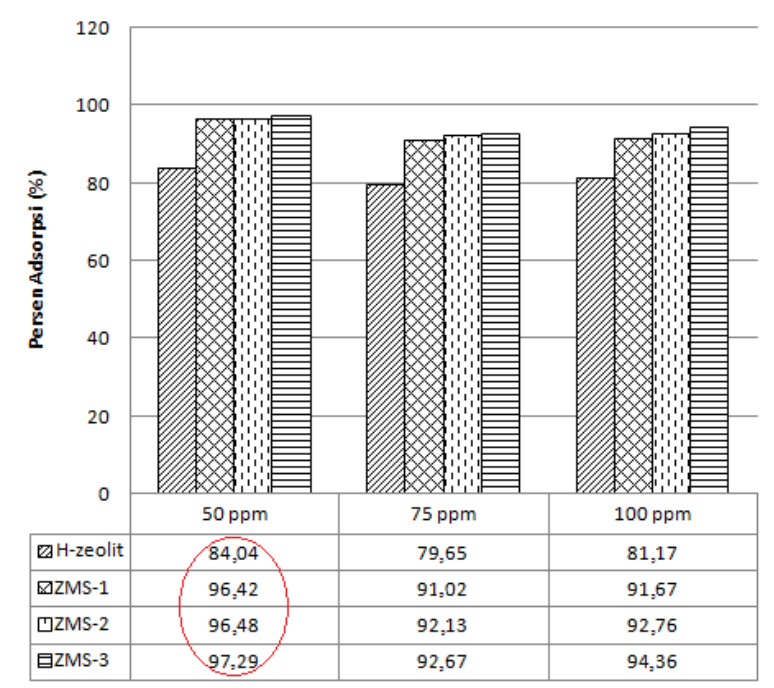

Gambar 4. Hasil adsorpsi zeolit terhadap ABS berbagai konsentrasi

Pada gambar 4, konsentrasi ABS 50 ppm merupakan konsentrasi maksimum dalam 
pengadsorpsian ABS oleh $\mathrm{H}$-zeolit maupun zeolit temodifikasi surfaktan (ZMS), dan persen adsorpsi terbesar ditunjukkan oleh ZMS-3 yaitu sebesar 97,29\%. Hal ini membuktikan bahwa dipermukaan zeolit telah terjadi bilayer surfaktan CTAB yang menyebabkan performanya lebih baik dibandingkan $\mathrm{H}$-zeolit, ZMS-1 atau ZMS-2. Terbentuknya bilayer pada ZMS-3 ini menyebabkan interaksi van der waals [2] antara muatan positif pada permukaan bilayer zeolit dengan muatan negatif dari surfaktan anion ABS, sehingga penjerpannya terhadap ABS lebih maksimal. Kemampuan adsorpsi ZMS-2 lebih baik dibandingkan ZMS-1, hal ini wajar terjadi sebab pada saat penambahan CTAB di bawah CMC permukaan zeolit masih belum berinteraksi sempurna dengan CTAB. Namun, untuk kondisi ZMS-2 dimungkinkan seluruh permukaan zeolit telah tertutupi oleh rantai metil dari CTAB yang menyebabkan interaksi hidrofobik antara permukaan monolayer zeolit dengan ABS. Adsorpsi dapat pula terjadi pada $\mathrm{H}$-zeolit, walaupun performanya tidak lebih baik dibandingkan dengan adsorpsi oleh ZMS-1, ZMS-2 dan ZMS-3, hal ini dikarenakan pada saat adsorpsi ABS dengan $\mathrm{H}$-zeolit, terjadi interaksi elektrostatik antara muatan positif dari permukaan zeolit $\left(\mathrm{H}^{+}\right)$dengan muatan negatif dari anionik $\mathrm{ABS}$ $\left(\mathrm{SO}_{3}-\right)$, mengakibatkan $\mathrm{H}$-zeolit mampu mengadsorpsi surfakatan ABS. Gambar 5, merupakan perkiraan skema kejadian saat adsorpsi surfaktan ABS dengan $\mathrm{H}$-Zeolit dan ZMS berbagai variasi konsentrasi CTAB berdasarkan CMC-nya yang mengacu pada penelitian Taffarel dan Rubio [2] dan Chutia dkk. [13].
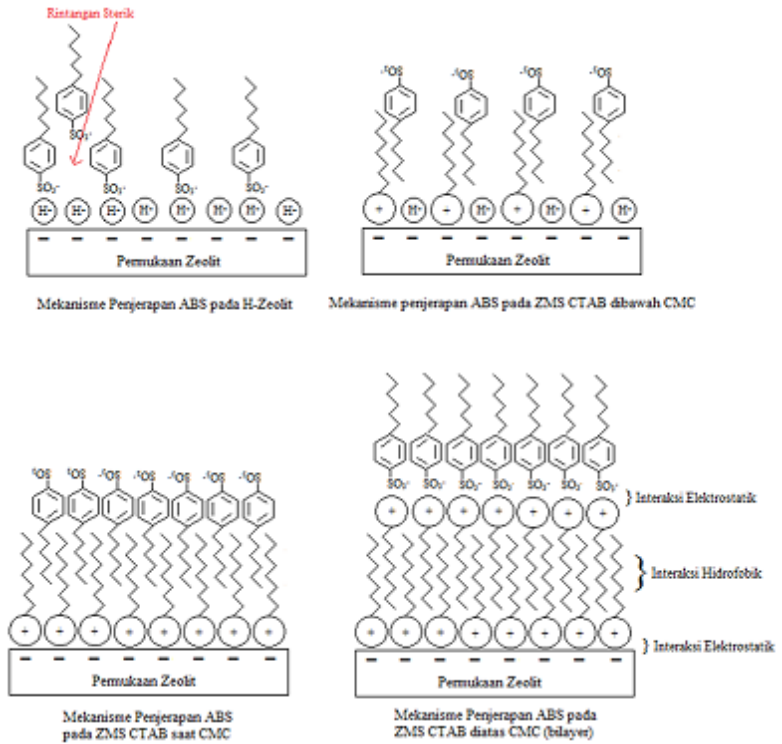

Gambar 5. Mekanisme penjerapan ABS

\section{Pengaruh Parameter Waktu Kontak}

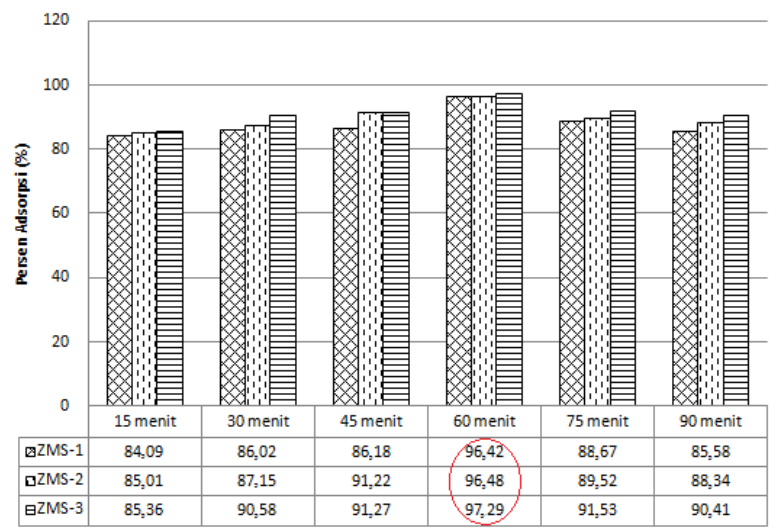

Gambar 6. Hasil adsorpsi terhadap $25 \mathrm{~mL}$ larutan ABS $50 \mathrm{ppm}$ dengan variasi waktu kontak

Pada Gambar 6, waktu optimum untuk adsorpsi ABS oleh zeolit termodifikasi surfaktan adalah 60 menit, dimana waktu ini menunjukkan persen adsorpsi terbesar yaitu 96,42 \% untuk ZMS-1, 96,48 \% untuk ZMS-2, dan 97,29\% untuk ZMS-3. Hal ini menjelaskan dalam waktu 60 menit telah terjadi kesetimbangan antara adsorben zeolit termodifikasi CTAB dengan adsorbat ABS. Namun pada saat setelah kondisi optimum terjadi penurunan kemampuan adsorpsi, hal ini dapat terjadi karena proses adsorpsi ini merupakan adsorpsi fisika yang dapat membuat senyawa ABS terlepas kembali kedalam larutan dengan adanya pengadukan yang terlalu lama.

\section{Kesimpulan}

Zeolit alam yang sudah teraktivasi $\mathrm{NH} 4 \mathrm{Cl}$ telah berhasil dimodifikasi dengan surfaktan CTAB (Cetiltrimethylammonium Bromida). Daya jerap paling tinggi diperlihatkan oleh ZMS-3 yaitu zeolit termodifikasi CTAB dengan konsentrasi $100 \mathrm{mM}$ (di atas CMC) sebesar 97,29\% pada konsentrasi ABS 50 ppm dengan waktu kontak 60 menit.

\section{Daftar Pustaka}

[1] Roberto Leyva-Ramos, Effect of temperature and ph on the adsorption of an anionic detergent on activated carbon, Journal of Chemical Technology \& Biotechnology, 45, 3, (1989) 231-240 10.1002/jctb.280450308

[2] Silvio R. Taffarel, Jorge Rubio, Adsorption of sodium dodecyl benzene sulfonate from aqueous solution using a modified natural zeolite with CTAB, Minerals Engineering, 23, 10, (2010) 771-779 http://dx.doi.org/10.1016/j.mineng.2010.05.018

[3] Zhuo Guan, Xiang-Yu Tang, Taku Nishimura, YuMing Huang, Brian J. Reid, Adsorption of linear alkylbenzene sulfonates on carboxyl modified multi-walled carbon nanotubes, Journal of Hazardous Materials, 322, (2017) 205-214 http://dx.doi.org/10.1016/j.jhazmat.2016.02.067

[4] Maulidah, Studi adsorpsi ABS (Alkyl Benzene Sulphonate) dari limbah rumah tangga Desa Ngadirgo menggunakan arang tempurung kelapa 
(coconut shells), in: Jurusan Kimia, Universitas Islam Negeri Walisongo, Semarang, 2015.

[5] Selli Renata Sari, Kajian Adsorpsi Linear Alkilbenzena Sulfonat (Las) Menggunakan Magnetit, in: Jurusan Kimia, Universitas Negeri Semarang, Semarang, 2015.

[6] Housheng Xia, Chun-Hui Zhou, Dongshen Tong, Junjun Chen, Weihua Yu, Shaomin Liu, Preparation and catalysis in epoxidation of allyl chloride of zeolitic titanosilicate-1/smectitic clay minerals, Applied Clay Science, 53, 2, (2011) 279-287 http://dx.doi.org/10.1016/j.clay.2011.04.014

[7] Di Zhang, Chun-Hui Zhou, Chun-Xiang Lin, DongShen Tong, Wei-Hua Yu, Synthesis of clay minerals, Applied Clay Science, 50, 1, (2010) 1-11 http://dx.doi.org/10.1016/j.clay.2010.06.019

[8] Chun Hui Zhou, An overview on strategies towards clay-based designer catalysts for green and sustainable catalysis, Applied Clay Science, 53, 2, (2011) http://dx.doi.org/10.1016/j.clay.2011.04.016

[9] Sriatun, Dimas Buntarto, Adi Darmawan, Pengaruh Penambahan Surfaktan Hexadecyltrimethylammonium (HDTMA) pada Zeolit Alam Terdealuminasi terhadap Kemampuan Mengadsorpsi Fenol, Jurnal Kimia Sains Dan Aplikasi, 11, 1, (2008) 20-24

[10] Huijuan Wei, Sujuan Xie, Kefeng Liu, Wenjie Xin, Xiujie Li, Shanhe Liu, Shunming Gu, Shenglin Liu, Longya Xu, CTAB modification of MCM-49 zeolite containing HMI and its acylation of anisole, Chinese Journal of Catalysis, 36, 10, (2015) 1766-1776 http://dx.doi.org/10.1016/S1872-2067(15)60887-7

[11] Jailson A. Araújo, Fernanda T. Cruz, Ivana H. Cruz, Dilson Cardoso, Encapsulation of polymers in CTAMCM-41 via microemulsion, Microporous and Mesoporous Materials, 180, (2013) 14-21 http://dx.doi.org/10.1016/j.micromeso.2013.05.010

[12] Ahmet Gürses, Kübra Güneş, Ferda Mindivan, Mehtap Ejder Korucu, Metin Açıkyıldız, Çetin Doğar, The investigation of electrokinetic behaviour of micro-particles produced by CTA+ ions and $\mathrm{Na}-$ montmorillonite, Applied Surface Science, 318, (2014) 79-84 http://dx.doi.org/10.1016/j.apsusc.2014.01.036

[13] Pratap Chutia, Shigeru Kato, Toshinori Kojima, Shigeo Satokawa, Adsorption of $\mathrm{As}(\mathrm{V})$ on surfactant-modified natural zeolites, Journal of Hazardous Materials, 162, 1, (2009) 204-211 http://dx.doi.org/10.1016/j.jhazmat.2008.05.024

[14] Dita Setiawati, Lia Destiarti, Nelly Wahyuni, Pemanfaatan Zeolit A Termodifikasi Hexadecyltrimethylammonium (HDTMA) Sebagai Adsorben Fosfat, Jurnal Kimia Khatulistiwa, 4, 2, (2015)

[15] He Hongping, Frost L. Ray, Zhu Jianxi, Infrared study of HDTMA+ intercalated montmorillonite, Spectrochimica Acta Part A: Molecular and Biomolecular Spectroscopy, 60, 12, (2004) 28532859 http://dx.doi.org/10.1016/j.saa.2003.09.028

[16] Zhaohui Li, Wei-Teh Jiang, Hanlie Hong, An FTIR investigation of hexadecyltrimethylammonium intercalation into rectorite, Spectrochimica Acta Part A: Molecular and Biomolecular Spectroscopy,
71 ,
4,
(2008)
http://dx.doi.org/10.1016/j.saa.2008.05.015
$1525-1534$ 